\title{
Pathogenic effect of interleukin-17A in induction of Sjögren's syndrome-like disease using adenovirus-mediated gene transfer
}

\author{
Cuong Q Nguyen ${ }^{1,2,3,4^{*}}$, Hongen Yin ${ }^{5}$, Byung Ha Lee ${ }^{3}$, Wendy C Carcamo ${ }^{3}$, John A Chiorini ${ }^{5}$, Ammon B Peck ${ }^{3,4,6}$
}

\begin{abstract}
Introduction: Sjögren's syndrome (SS) involves a chronic, progressive inflammation primarily of the salivary and lacrimal glands leading to decreased levels of saliva and tears resulting in dry mouth and dry eye diseases. Seminal findings regarding $T_{H} 17$ cell populations that secrete predominantly interleukin (IL)-17A have been shown to play an important role in an increasing number of autoimmune diseases, including SS. In the present study, we investigated the function of IL-17A on the development and onset of SS.

Methods: Adenovirus serotype 5 (Ad5) vectors expressing either IL-17A or LacZ were infused via retrograde cannulation into the salivary glands of C57BL/6J mice between 6 and 8 weeks of age or between 15 and 17 weeks of age. The mice were characterized for SS phenotypes.

Results: Disease profiling indicated that SS-non-susceptible C57BL/6J mice whose salivary glands received the Ad5IL17A vector developed a SS-like disease profile, including the appearance of lymphocytic foci, increased cytokine levels, changes in antinuclear antibody profiles, and temporal loss of saliva flow.

Conclusions: Induction of SS pathology by IL-17A in SS-non-susceptible mice strongly suggests that IL-17A is an important inflammatory cytokine in salivary gland dysfunction. Thus, localized anti-IL17 therapy may be effective in preventing glandular dysfunction.
\end{abstract}

\section{Introduction}

Sjögren's syndrome (SS) is a chronic, systemic autoimmune disease characterized most notably by development of dry eyes and dry mouth manifestations, indicative of secretory dysfunction of the lacrimal and salivary glands [1-3]. Although the etiology of SS remains unknown, intensive studies of an ever-expanding number of animal models is beginning to unravel the genetic, molecular and immunological basis for this disease [1]. Previous studies have implicated critical roles for both interferon- $\gamma$ (IFN- $\gamma$ ) and interleukin (IL)- 4 in the development and onset of SS-like disease in NOD/Lt and C57BL/6.NODAec1Aec2 mice $[4,5]$, strongly suggesting involvement of $\mathrm{T}_{\mathrm{H}} 1$ and $\mathrm{T}_{\mathrm{H}} 2$ cell populations, respectively. While IFN- $\gamma$ regulates cell-mediated immunity through activation of macrophages, $\mathrm{NK}$ cells and $\mathrm{CD} 8^{+} \mathrm{T}$ cells, this cytokine

\footnotetext{
* Correspondence: Nguyen@pathology.ufl.edu

${ }^{1}$ Eli and Edythe L. Broad Institute, 7 Cambridge Center, Cambridge, MA 02142, USA

Full list of author information is available at the end of the article
}

appears to predispose these SS-susceptible mice by retarding salivary gland organogenesis, especially proliferation of acinar tissue [5]. This delay in acinar cell maturation has been postulated to prevent expression of cellular antigens at the critical time of self-tolerance, resulting in inefficient clonal deletion of acinar tissuereactive $\mathrm{T}$ cells. In contrast to the role of IFN- $\gamma$ both prior to and during development of SS, IL-4 appears to be essential during development of adaptive immunity and subsequent onset of glandular dysfunction. Specifically, IL-4 was shown to be necessary for proper isotypic switching, regulating B lymphocyte synthesis of pathogenic IgG1 anti-muscarinic acetylcholine type III receptor (M3R) autoantibodies [6,7].

Although these earlier studies have implicated both $\mathrm{T}_{\mathrm{H}} 1$ and $\mathrm{T}_{\mathrm{H}} 2$ cell-associated functions in the development and onset of clinical SS, recent identification of the $C D 4^{+} \mathrm{T}_{\mathrm{H}} 17$ memory cells within the lymphocytic focus (LF) of lacrimal and salivary glands of $\mathrm{SS}^{\mathrm{s}} \mathrm{C} 57 \mathrm{BL} /$ 6.NOD-Aec1Aec2 mice, as well as minor salivary glands 
of human SS patients, greatly expands the potential complexity in deciphering the autoimmune response underlying SS $[8,9]$. The $\mathrm{T}_{\mathrm{H}} 17$ cell population, while clearly a subset of $\mathrm{CD}^{+}$memory effector $\mathrm{T}$ cells, appears to be distinct from, and unrelated to, either the $\mathrm{T}_{\mathrm{H}} 1$ or $\mathrm{T}_{\mathrm{H}} 2$ cell lineages [10-14]. $\mathrm{T}_{\mathrm{H}} 17$ effector cells secrete at least one of the six cytokines belonging to the IL-17 family, that is, IL-17A, IL-17B, IL-17C, IL-17D, IL-25 and/or IL-17F; however, IL-17A, the signature cytokine, has received the greatest attention in studies of autoimmune diseases [15]. The IL-17 cytokines are potent pro-inflammatory molecules, actively involved in tissue inflammation via induction of pro-inflammatory cytokine and chemokine expressions [16]. In addition, IL-17 is involved in the mobilization, maturation and migration of neutrophils via the release of IL- 8 at the site of injury [17]. Interestingly, IL-17A is known to regulate Foxp3 $+\mathrm{T}_{\text {Reg }}$ cells and vice versa [18].

While $\mathrm{T}_{\mathrm{H}} 17$ cells have been implicated in several autoimmune diseases (for example, Crohn's disease $[19,20]$, experimental autoimmune encephalomyelitis (EAE) [21], collagen-induced arthritis (CIA) [21], SS [8] and others $[2,3])$, this characteristic may require signaling from $\mathrm{T}_{\mathrm{H}} 1$ cells already present in the lesion [3]. In any event, recent observational studies in SS patients and animal models of primary SS have identified the presence of IL-17A and its activating cytokine IL-23 in the lymphocytic infiltrates of the exocrine glands, as well as higher levels of circulating IL-17A in both sera and saliva [8], raising the question of the importance of IL-17 in SS. Thus, the goals of the present study were to determine whether IL-17A can directly influence the pathology leading to the onset of SS-like disease by administrating exogenous IL-17A to the salivary glands at specific time points.

\section{Materials and methods}

\section{Animals}

SS non-susceptible C57BL/6J mice were bred and maintained under specific pathogen-free conditions. The animals were maintained on a 12-hr light-dark schedule and provided food and acidified water ad libitum. At times indicated in the text, mice were euthanized by cervical dislocation following deep anesthetization with isoflurane, after which organs were freshly explanted for analyses. Both the breeding and use of these animals for the present studies were approved by the University of Florida's IACUC and IBC. Salivary glands of mice were cannulated with mouse IL-17A-expressing Ad5-IL17A vector using retrograde injections at either 7 weeks (wks) of age $(n=11)$ or 16 wks of age $(n=8)$. In addition, mice at 6 wks $(n=4)$ and 15 wks $(n=4)$ were randomly selected and used as pre-treated or baseline analysis. Age- and sex-matched control C57BL/6J mice
( $n=10$ per age group) received the Ad5-LacZ control vector using the same protocols.

\section{Production of Ad5-LacZ and Ad5-IL17A vectors}

The recombinant adenovirus vectors used in this study were generously provided by Dr. Jay K. Kolls (Children's Hospital of Pittsburgh, Pittsburgh, PA, USA). These vectors are based on the first generation adenovirus serotype 5 (Ad5) and shown to produce their appropriate and functional mouse IL- 17A and LacZ products [22-24]. To obtain sufficient viral vectors for the present studies, each recombinant vector was amplified in HEK293 cells, purified by two rounds of $\mathrm{CsCl}$ gradient centrifugation, then dialyzed against $100 \mathrm{mM}$ Tris- $\mathrm{HCl}$ (pH 7.4), $10 \mathrm{mM} \mathrm{MgCl}_{2}$ and $10 \%$ (v/v) glycerol, as described elsewhere [25].

\section{Retrograde salivary gland cannulation of Ad5-LacZ or Ad5-IL17A vectors}

Previous studies have demonstrated that retrograde salivary gland cannulation is an effective method to direct local gene expression in the salivary glands [26-28]. In brief, prior to cannulation, each mouse was anesthetized with a ketamine:xylazine mixture $(100 \mathrm{mg} / \mathrm{mL}, 1 \mathrm{~mL} / \mathrm{kg}$ body weight; Fort Dodge Animal Health, Fort Dodge, IA, USA) and xylazine $(20 \mathrm{mg} / \mathrm{mL}, 0.7 \mathrm{~mL} / \mathrm{kg}$ body weight; Phoenix Scientific, St. Joseph, MO, USA)) intramuscularly. Stretched PE-10 polyethylene tubes were inserted into each of the two openings of the salivary ducts. After securing the cannulas, the mouse received an intramuscular injection of atropine $(1 \mathrm{mg} / \mathrm{kg})$, followed 10 minutes later by a slow, steady injection of viral vector. Each salivary gland received $50 \mu \mathrm{l}$ of vector solution containing $10^{7}$ viral particles). The cannulas were removed five minutes later to ensure successful cannulation.

\section{Measurement of saliva flow}

To measure stimulated saliva flow, individual nonanesthetized mice were weighed and given an intraperitoneal injection of $100 \mu \mathrm{l}$ of phosphate-buffered saline (PBS) containing isoproterenol $(0.02 \mathrm{mg} / \mathrm{ml})$ and pilocarpine $(0.05 \mathrm{mg} / \mathrm{ml})$. Saliva was collected for $10 \mathrm{~min}$ utes from the oral cavity of individual mice using a micropipette starting 1 minute after injection of the secretagogue. The volume of each saliva sample was measured. Prior to vector cannulation and again at each time-point designated in the text, saliva and sera were collected from each mouse. Samples were stored at $-80^{\circ} \mathrm{C}$ until analyzed.

\section{Determination of cytokines levels}

Measurements of IL-6 and IL-17A cytokine levels in sera samples were performed by an independent 
contractor (Millipore, Billerica, MA, USA) using Luminex ${ }^{\circledR}$ platform.

\section{Intracellular cytokine staining and flow cytometric analysis}

Spleens were freshly explanted, gently minced through stainless steel sieves, suspended in PBS and centrifuged (1,200 rpm for five minutes). Erythrocytes were lysed by seven-minute incubation in $0.84 \% \mathrm{NH} 4 \mathrm{Cl}$. The resulting leukocyte suspensions were washed two times in PBS, counted and resuspended inculture media (RPMI 1640 medium, 10\% FBS, $2 \mathrm{mM}$ L-glutamine, $0.05 \mathrm{mM} \beta$ mercaptoethanol) at a density of $2 \times 10^{6}$ cells $/ \mathrm{ml}$. One million cells were pipetted to individual wells of a 24well microtiter plate pre-coated with anti-CD3 $(10 \mu \mathrm{g} / \mathrm{ml})$ and anti-CD28 antibodies $(2 \mu \mathrm{g} / \mathrm{ml})$ for $\mathrm{T}$ cell activation. Cells were incubated for five hours with Leukocyte Activation Cocktail containing GolgiPlug $(2 \mu \mathrm{l} / \mathrm{ml})$. Collected cells were fixed and permeabilized using Cytofix/CytopermFixation/Permeabilization. Flow cytometric acquisition for intracellular staining was performed following staining with PE-Cy5-conjugated anti-mouse CD4, FITCconjugated anti-IFN- $\gamma$ and PE-conjugated anti-IL-17AA. The cells were counted on a FACSCalibur (BD, Franklin Lakes, NJ, USA) and analyzed by FCS Express (De Novo Software, Los Angeles, CA, USA).

\section{Histology}

Following euthanasia, whole salivary glands containing submandibular, sublingual, and parotid glands were surgically removed from each mouse and placed in 10\% phosphate-buffered formalin for 24 hrs. Fixed tissues were embedded in paraffin and sectioned at $5 \mu \mathrm{m}$ thickness. Paraffin-embedded sections were de-paraffinized by immersing in xylene, followed by dehydrating in ethanol. The tissue sections were prepared and stained with hematoxylin and eosin (H\&E) dye. Stained sections were observed under a microscope for glandular structure and leukocyte infiltration determination. A doubleblinded procedure was used to enumerate leukocytic infiltrations (lymphocytic foci) in the histological sections of salivary glands. Lymphocytic foci (LF) were defined as aggregates of $>50$ leukocytes quantified per each histological section. Calculations were based on one histological section per mouse.

\section{Immunofluorescent staining for CD3+T cells and B220+B cells}

Histological sections of salivary glands were incubated with rat anti-mouse B220 (BD Pharmingen, San Jose, CA, USA) and goat anti-mouse CD3 (Santa Cruz Biotechnology, Santa Cruz, CA, USA), followed by incubation with Texas Red-conjugated rabbit anti-rat IgG (Biomeda, Foster City, CA, USA) and FITC-conjugated rabbit anti-goat IgG (Sigma-Aldrich, St. Louis, MO, USA). The slides were mounted with DAPI-mounting medium (Vector Laboratories, Burlingame, CA, USA). Sections were observed at 200X magnification using a Zeiss Axiovert $200 \mathrm{M}$ microscope.and images were obtained with AxioVs40 software (Ver. 4.7.1.0, Zeiss) (Carl Zeiss, Thornwood, NY, USA). Enumeration of B, $T$ cells and total number of nuclei in the LF were performed using Mayachitra imago software (Mayachitra, Inc, Santa Barbara, CA, USA).

\section{Immunohistochemical staining for IL17A in salivary glands}

Immunohistochemical staining for IL17A were carried out as previously described [8]. In brief, paraffinembedded salivary glands were deparaffinized by immersion in xylene, followed by antigen retrieval with $10 \mathrm{mM}$ citrate buffer, $\mathrm{pH}$ 6.0. Tissue sections were incubated overnight at $4^{\circ} \mathrm{C}$ with anti-IL-17A antibody (Santa Cruz Biotechnology). Isotype controls were done with rabbit IgG. The slides were incubated with biotinylated goat anti-rabbit IgG followed by horseradish peroxidaseconjugated strepavidin incubation using the Vectastain ABC kit. The staining was developed by using diaminobenzidine substrate (Vector Laboratories), and counterstaining was performed with hematoxylin. Sections were observed at 200X magnification using a Zeiss Axiovert $200 \mathrm{M}$ microscope. And images were obtained with AxioVs40 software (Ver. 4.7.1.0, Zeiss) (Carl Zeiss). Enumeration of IL17A-positive cells was performed on the entire histological sections of the whole salivary glands using Mayachitra imago software (Mayachitra, Inc.), although lymphocytic infiltrations are normally seen only in the submandibular glands.

\section{Detection of antinuclear antibodies (ANA) in the sera}

ANA in the sera of mice were detected using HEp-2 ANA kit (INOVA Diagnostics, Inc., San Diego, CA, USA). All procedures were performed per manufacturer's instructions. In brief, HEp-2 fixed substrate slides were overlaid with appropriate mouse sera diluted 1:40, $1: 80$ and 1:160. Slides were incubated for one hour at room temperature in a humidified chamber. After three washes for five minutes with PBS, the substrate slides were covered with Alexa 488-conjugated goat antimouse IgG (H/L) (Invitrogen Inc, Carlsbad, CA, USA) diluted 1:100 for 45 minutes at room temperature. After three washes, fluorescence was detected by fluorescence microscopy at 200X magnification using a Zeiss Axiovert $200 \mathrm{M}$ microscope and all images were obtained with AxioVs40 software with constant exposure of 0.3 seconds (Carl Zeiss). Negative controls are secondary antibody only and positive controls are standard serum with nuclear speckled pattern provided with the kits. 
Data presented in the results are from slides using 1:40 dilutions of sera from each experimental group.

\section{Statistical analyses}

Statistical evaluations were determined by using the Mann-Whitney U test generated by the GraphPad InStat software (GraphPad Software, La Jolla, CA, USA). The two-tailed $P$-value $<0.05$ was considered significant.

\section{Results}

Induction of IL-17A and IL- 6 cytokine levels in sera following transduction with Ad5-IL17A vector

Adenoviral vectors have been reported to show peak gene expressions around Day 5 post-infusion and then persist for approximately two weeks [29]. In the current study, immunohistochemical staining for the presence of LacZ protein in the infused salivary glands demonstrated that optimal transduction efficiency was approximately $26 \pm 5 \%$ at two weeks post-infusion which decreased to $15 \pm 3 \%$ by nine weeks post-infusion. The cells within the salivary glands positive for LacZ expression were predominantly ductal cells, as expected, and acinar cells (data not shown), indicating the virus was capable of passing through the ducts.

To determine if transduction of salivary glands with IL-17A alters the serum cytokine profiles, serum preparations were assessed for temporal changes in proinflammatory cytokine levels. Sera of treated mice were collected at Days 5 and 12 post-treatment to determine the efficacy of the IL-17A expressing viral vectors to affect cytokine secretions. As shown in Figure 1, C57BL/ $6 \mathrm{~J}$ mice treated with the Ad5-IL17A vector at $10^{7}$ viral particles per salivary gland exhibited a marked increase

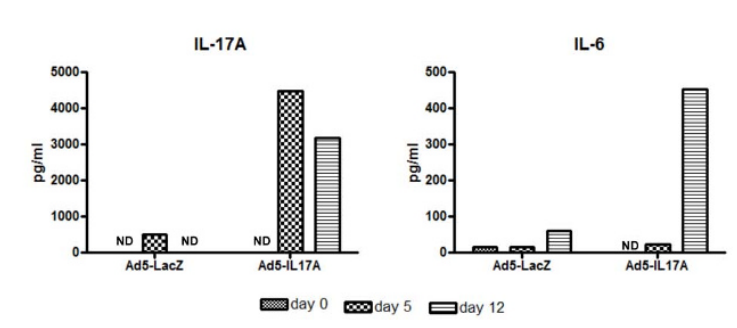

Figure 1 Rapid changes in IL-17A and IL-6 serum cytokine concentrations in $\mathrm{C57BL} / 6 \mathrm{~J}$ mice following vector cannulations. Sera were prepared from blood collected from individual five-week old mice $(n=4)$ randomly chosen one week prior to vector treatment (Day 0 on the graph). Mice were allowed to acclimate for seven days, followed by vector instillation of each salivary gland with $50 \mu \mathrm{l}$ of vector solution containing $10^{7}$ viral particles of either Ad5-LacZ or Ad5-IL17A vector. Sera were again prepared from blood collected from individual mice $(n=11)$ at Day 5 and Day 12 post-treatment. Concentrations of cytokines were determined using the Luminex platform. To ensure sufficient quantities for testing, the sera of three individual mice of each experimental group were pooled. ND, not detected indicates levels below threshold detection. in the levels of serum IL-17A compared to baseline levels or with C57BL/6J mice receiving the control Ad5LacZ vector at $10^{7}$ viral particles per salivary gland, demonstrating the efficacy of this viral vector to produce IL-17A. In addition, Ad5-IL17A-treated C57BL/6J mice also secreted elevated amounts of the IL-17A-related cytokine IL-6 following cannulation. Thus, the vectors gain access into the glands and apparently secrete IL$17 \mathrm{~A}$ in quantities that elevate systemic levels.

\section{Increased numbers of IL-17A-producing CD4+ T cells in the spleens of Ad5-IL17A transduced mice}

As mentioned previously, salivary glands were cannulated with Ad5-IL17A vector at either 7 wks or $16 \mathrm{wks}$ of age. The time points chosen are based on extensive studies of the development and onset of disease in our C57BL/6.NOD-Aec1Aec2 mouse model of SS [1-3,30,31]. The two time points selected represent the innate and adaptive immune response phases, respectively, in the disease model, thus they were chosen to mimic these changes in the parental C57BL/6 mouse. Microarray analyses examined the temporal differential gene expression of salivary and lacrimal glands of C57BL/6 mice revealed gradual change in pathophysiological related genes from 16 to 20 wks of age, concomitantly, leukocyte infiltration in the exocrine glands is often observed at these ages $[32,33]$. Thus, it is important to examine the role of IL17A in the development of SS prior and post to any pathophysiological changes.

Mice treated with Ad5-IL17A or Ad5-LacZ at either 7 wks or 16 wks of age were euthanized at 26 and 27 wks of age, that is, 19 wks and 11 wks post-treatment, respectively. Splenocytes were isolated from individual mice and examined for the number of IFN- $\gamma$ and IL-17A secreting CD4+T cells. Representative data, presented in Figure 2b, c, revealed that the number of IL$17 \mathrm{~A}$ secreting $\mathrm{CD} 4+\mathrm{T}$ cells in the spleens of mice receiving the Ad5-IL17A vector at seven weeks of age was approximately two-fold higher than mice receiving the control Ad5-LacZ vector, while the number of IFN- $\gamma$ secreting CD4+T cells was approximately half at time of analysis. Similarly, the number of IL-17A secreting CD4 $+\mathrm{T}$ cells in the spleens of mice receiving the Ad5-IL17A vector at 16 wks of age was approximately seven-fold higher than mice receiving the control Ad5-LacZ vector, while the number of IFN- $\gamma$ secreting CD4+T cells was less than $50 \%$ at time of analysis (Figure 2e, f). Results of a similar analysis with untreated mice performed one week prior to vector cannulations are presented in Figures $2 \mathrm{a}, \mathrm{d}$. These data suggest that even though the Ad5 vector is considered locally restricted, the effect in C57BL/6 J mice appeared systematic. More importantly, the systemic effects of IL17A in Ad5 appears to be correlated with the duration of gene expression after vector 


\section{Early treatment}

(a) 6 wks old mice (Pre-treatment)

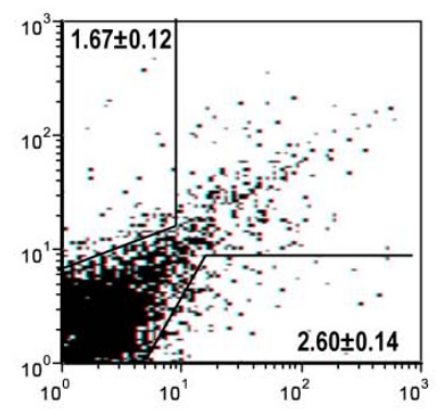

\section{Late treatment}

(d) 15 wks old mice (Pre-treatment)

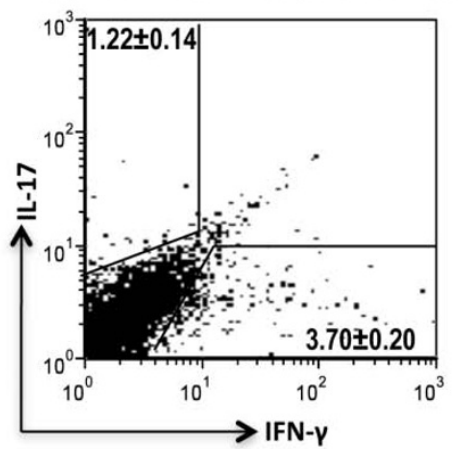

(b) 26 wks old mice: Ad5-LacZ

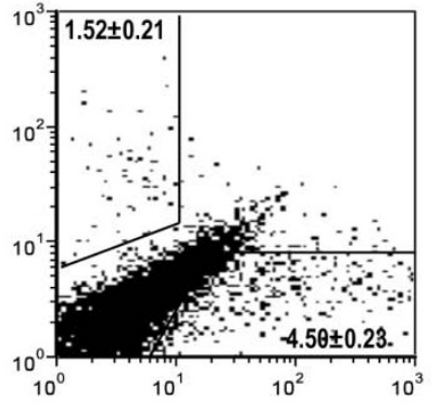

(e) 27 wks old mice: Ad5-LacZ

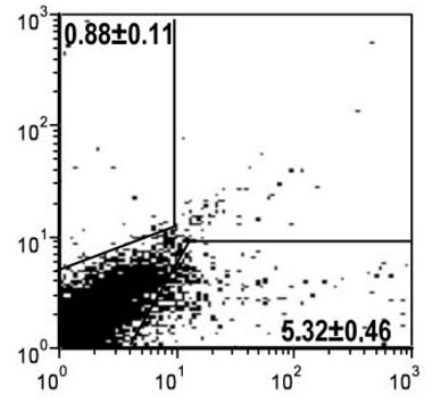

(c) 26 wks old mice: Ad5-IL17A

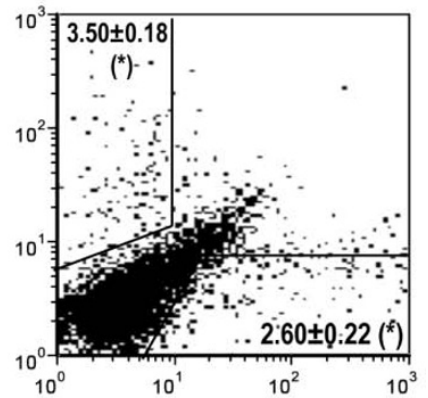

(f) $\mathbf{2 7}$ wks old mice: Ad5-IL17A

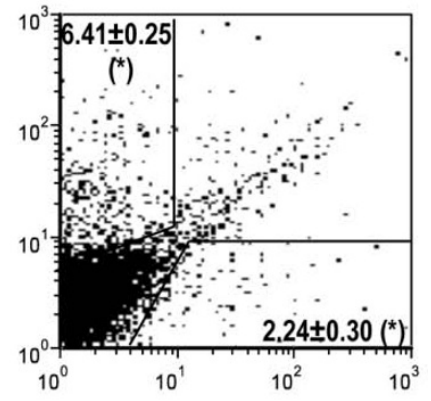

Figure 2 Intracellular staining for IL-17A and IFN- $\gamma$ secreting CD4 ${ }^{+}$T cells in spleens of Ad5-IL17A-treated mice. Splenic leukocytes prepared from C57BL/6J mice $(n=4)$ at 6 wks of age (one wk prior to vector treatment) and 26 wks old (19 wks post vector treatment), considered early treatment $(\mathbf{a}-\mathbf{c})$, or splenic leukocytes prepared from C57BL/6J mice $(n=4)$ at 15 wks of age ( 1 wk prior to vector treatment) and 27 wks old (11 wks post vector treatment), considered late treatment (d-f) were examined for the presence of intracellular IL-17A and IFN- $\gamma$ gated on $\mathrm{CD}^{+}{ }^{+} \mathrm{T}$ cells following a 5-hr in-vitro activation with anti-CD3E and anti-CD28 in Leukocyte Activation Cocktail containing GolgiPlug. Flow cytometric acquisition was performed by staining with PE-Cy5-conjugated rat anti-CD4, FITC-conjugated rat anti-IFNy and/or PE-Conjugated rat anti-IL-17A. Data were analyzed by FCS Express. Flow cytometric images shown are from one representative analysis of two independent experiments that examined two different mice within each experiment. Data presented as mean \pm SEM for $n=4$ per group and statistical analyses were performed comparing the means of the Ad-LacZ and Ad-IL17A treated groups at 26 wks and 27 wks of early and late treatment, respectively. $\left({ }^{*}\right)$ indicates $P<0.5$ using the Mann-Whitney $U$ test.

cannulation as evidenced by the two-fold increase in the levels of IL-17A secreting cells at 19 wks post-treatment in younger mice but a seven-fold increase at $11 \mathrm{wks}$ post-treatment in the older group. However, one cannot rule out the possibility that different efficacies are achieved based on the status of disease development in different ages of mice.

\section{Induction of SS immune-pathology in C57BL/6 mice following treatment with Ad5-IL17A vector}

Lymphocyte infiltration of the salivary and/or lacrimal glands is a critical criterion for identification of the autoimmune phase of SS in both human and animal models. Although the number of LF present in the salivary and lacrimal glands does not often correlate directly with disease or its severity, SS patients and NOD-derived mouse strains exhibiting SS-like disease typically have lymphocytic infiltrates in their salivary glands. IL-17A appears to play a critical role in the development of LF and has recently been found to be present within LF in both SS patients and animal models [8]. Salivary glands of C57BL/6J mice following cannulation with Ad5-IL17A vector were examined for the presence of infiltrating leukocytes. Salivary glands retrieved from C57BL/6J mice treated with Ad5-LacZ vector at either 7 or 16 wks of age revealed that $10 \%$ (1 of 10) in each group had evidence of glandular infiltrations (Figure $3 \mathrm{a}, \mathrm{b}, \mathrm{g}, \mathrm{h}$; Table 1). This observation is consistent with the number of healthy, untreated C57BL/6J mice expected to have infiltration of the 

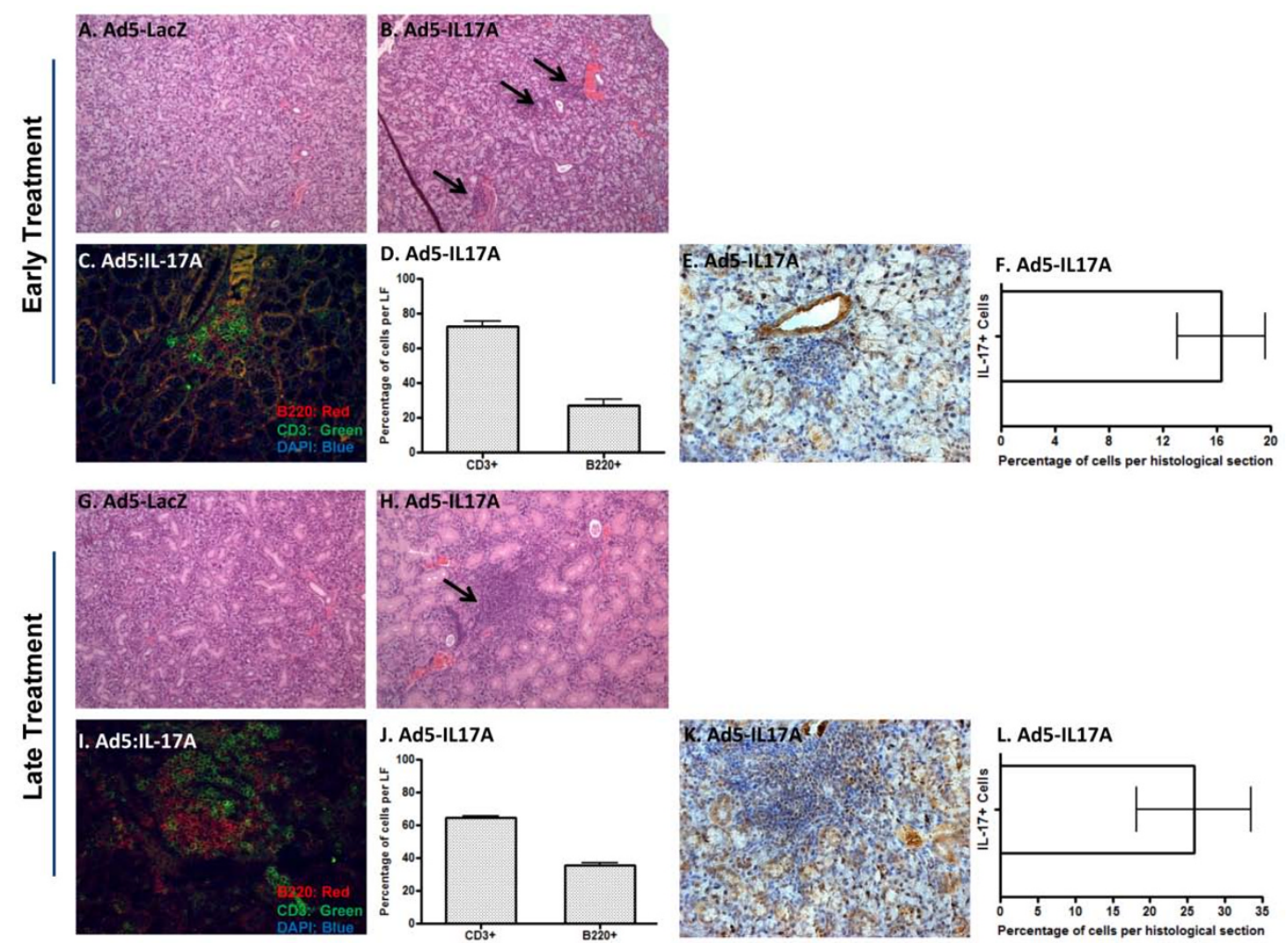

Figure 3 Histological examination of salivary glands. Salivary gland histology was examined at 19 wks post-vector infusions of mice treated at 7 wks of age (early treatment) or at 11 wks post-vector infusions of mice treated at 16 wks of age (late treatment). Panels show representative H\&E staining of salivary gland tissue from mice receiving early treatment with Ad5-LacZ ( $n=10)(a)$, or Ad5-IL17A ( $n=11)$ (b); fluorescent staining and enumeration of B and T cells in Ad5-IL17A treated mice (c and $\mathbf{d}$ ) and immunohistochemical staining and enumeration of IL-17A-positive cells in Ad5-IL 17A treated mice (e and f); H\&E staining of salivary gland tissue from mice receiving late treatment with Ad5-LacZ $(n=10)(\mathbf{g})$, or Ad5-IL17 $(n=8)(\mathbf{h})$; and fluorescent staining and enumeration of B and T cells in Ad5-IL17A treated mice (i and $\mathbf{j}$ ) and immunohistochemical staining and enumeration of IL-17A-positive cells in Ad5-IL17A treated mice (k and I). Black arrows indicate representative lymphocytic infiltrate.

salivary glands [8]. In contrast, salivary glands from C57BL/6 mice treated with Ad5-IL17A vector at seven weeks of age showed infiltrations in 91\% (10 of 11) with the mean LF per histological section numbering $4 \pm$ 1.32, while salivary glands from $\mathrm{C} 57 \mathrm{BL} / 6 \mathrm{~J}$ mice treated with Ad5-IL17A vector at 16 wks of age revealed

Table 1 Quantification of lymphocytic foci (LF) in salivary glands

\begin{tabular}{lcccccc}
\hline & \multicolumn{3}{c}{ Ad5:LacZ } & \multicolumn{3}{c}{ Ad5:IL17A } \\
\cline { 2 - 7 } & No LF & LF & Mean LF & No LF & LF & Mean LF \\
\hline Early & $9^{\mathrm{a}}(90 \%)^{\mathrm{b}}$ & $1(10 \%)$ & 1 & $1(9 \%)$ & $10(91 \%)$ & $4 \pm 1.32^{c}$ \\
Late & $9(90 \%)$ & $1(10 \%)$ & 1 & $2(25 \%)$ & $6(75 \%)$ & $2 \pm 0.83$ \\
\hline
\end{tabular}

${ }^{a}$ number of mice.

${ }^{b}$ percentage of mice.

'mean number of LF \pm SEM per histological salivary gland section. Ad5, Adenovirus serotype 5; IL, interleukin; LF, lymphocytic foci. infiltrations in $75 \%$ (6 of 8 ) with a mean LF number per histological section of $2 \pm 0.83$ (Table 1 ).

Besides the number of LF detected in the salivary glands of the experimental animals, immunofluorescent staining to detect $\mathrm{B}$ and $\mathrm{T}$ cells revealed further differences in the cellular composition of the infiltrations between mice administered Ad5-IL17A at an early or late stage. At time of euthanasia, C57BL/6J mice treated with Ad5-IL17A vector at 7 wks of age generally exhibited smaller foci containing fewer IL-17 positive cells compared to mice receiving the vector at 16 wks of age (Figure 3c-f, i-l). Consistent with previous observation, the smaller foci in mice treated at 7 wks of age may have resulted from the longer duration of time after cannulation (19 wks) reflecting the decreases in IL-17A serum levels and IL-17A- positive cell numbers. Detailed examination of IL-17A-positive cells revealed that a majority of IL-17A cells are present in the LF and ductal cells with smaller percentage of positive 
cells found in the epithelium and acinar cells. Nevertheless, these data support the concept that formation and maintenance of LF are due, in part, to the expression levels of IL17A in the salivary glands.

\section{Changes in ANA profiles following instillation of the Ad5-IL-17A vector}

With the appearance of $\mathrm{B}$ and $\mathrm{T}$ lymphocytes within the salivary glands of Ad5-IL17A treated C57BL/6 mice, plus the significant changes within their splenic $\mathrm{T}_{\mathrm{H}} 17$ and $\mathrm{T}_{\mathrm{H}} 1$ cell populations, the presence of circulating autoantibodies, specifically ANA, detectable by staining of HEp2 cells was examined. To identify the presence of ANA, the sera prepared from blood samples collected from each $\mathrm{C} 57 \mathrm{BL} / 6 \mathrm{~J}$ mouse both pre- and post-cannulation were tested for reactivity on HEp- 2 cells. As presented in Figure $4 \mathrm{a}$, the sera collected from C57BL/6J mice at six weeks of age or one week prior to vector treatment showed a general weakly diffused cytoplasmic and nuclear background staining of the individual target cells. However, sera collected 19 wks post-treatment from mice treated with Ad5-IL17A vector at 7 wks of age showed no cytoplasmic staining with course speckled staining and negative nucleoli, while Ad5-LacZ treated mice exhibited diffused cytoplasmic staining, weak but fine speckled nucleoplasmic staining with negative nucleoli (Figures 4b, c). Similar results were seen in C7BL/6J mice whose salivary glands were transduced with Ad5-IL17A vector at 16 wks of age in which the pattern was pronounced course speckled staining with no cytoplasmic staining and negative nucleoli at $29 \mathrm{wks}$ of age, or 11 wks post-treatment (Figures $4 \mathrm{~d}-\mathrm{f}$ ). Considering the functions of IL-17A, it is interesting to see a gradual and subtle change in ANA profile from diffused cytoplasmic/nuclear pattern to a distinct course nuclear speckled pattern, suggesting influence of IL-17A on the B cells repertoire.

\section{Induction of salivary gland dysfunction in C57BL/6J mice following cannulation with Ad5-IL17A vector}

To determine if the expression of exogenous IL-17A can induce salivary gland dysfunction, saliva volumes for each
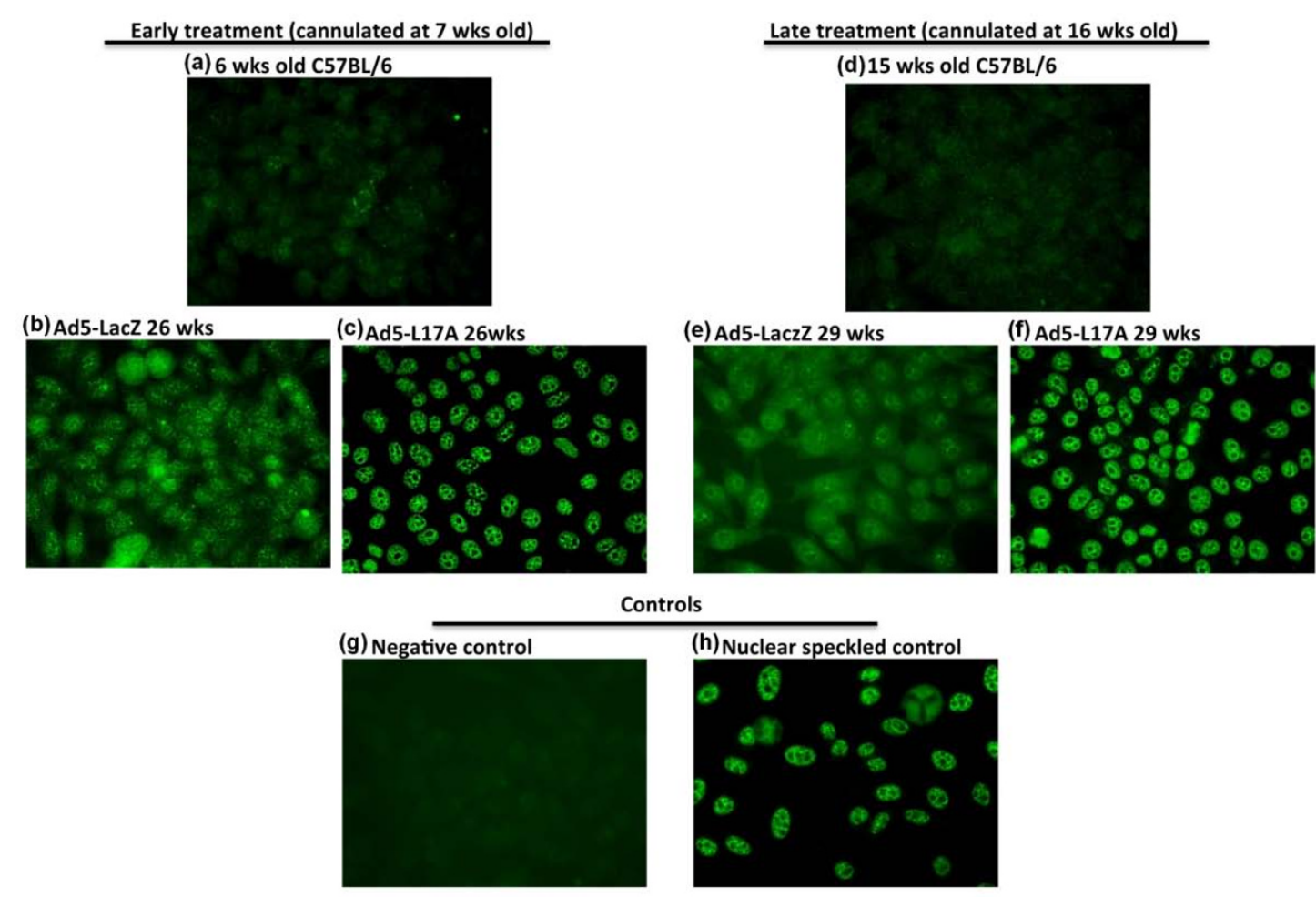

Controls

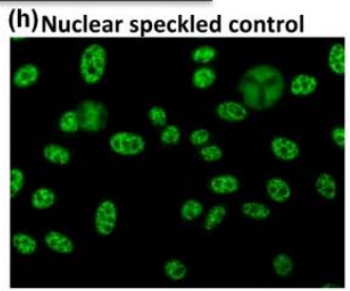

Figure 4 Identification of the antinuclear antibodies in sera of C57BL/6J mice. Representative patterns of cellular staining of HEp-2 cells by sera diluted at 1:40 prepared from sera taken from C57BL/6 mice cannulated with Ad5-LacZ or Ad5-IL17A vectors at 7 wks of age with pretreated mice (baseline) at 6 wks of age $(n=4)(\mathbf{a}-\mathbf{c})$, and cannulated at 16 wks of age with Ad5-LacZ or Ad5-IL17A and pre-treated mice (baseline) at 15 wks of age $(n=4)(\mathbf{d}-\mathbf{f})$ with negative control using secondary antibody only (g) and positive control with standard nuclear speckled serum (h). Representative patterns were determined with $n=4$ for two baselines and $n=7$ for each time point presented in the figure. Fixed HEp-2 substrate slides were incubated with individual mouse sera diluted 1:40, 1:80 and 1:160 followed by development with FITCconjugated goat anti-mouse lgG. Fluorescent patterns were detected by fluorescence microscopy at 400X magnification. 
mouse were measured at one week prior to treatment, then at three- to five-week intervals post-cannulation. C57BL/6J mice that received control Ad5-LacZ vector at seven weeks of age exhibited stable stimulated saliva volumes at seven weeks post treatment with a statistically non-significant increase in saliva volumes at 11 weeks post treatment. Nevertheless, C57BL/6J mice whose salivary glands were cannulated at seven weeks of age with Ad5-IL17A exhibited a significant and relatively rapid decrease in stimulated saliva volumes that was most pronounced at seven weeks post treatment, and this observation is seen even if the saliva volumes are converted to saliva flow rates based on weights of the mice. After seven weeks post treatment, these mice showed a slight recovery (Figure 5a). Similar results were observed with C57BL/6J mice cannulated at 16 wks of age with Ad5LacZ and Ad5-IL17A vectors; however, no saliva volume recovery was observed at time of euthanization (that is, 11 wks post-treatment) (Figure 5b). Whether a reversal of this inhibition would occur in these older animals will require further studies. Thus, saliva secretions of mice receiving the Ad5-IL17A vector were significantly decreased one to two months post-treatment when compared to secretions of mice receiving the Ad5-LacZ vector.

\section{Discussion}

The $\mathrm{T}_{\mathrm{H}} 17$-derived IL-17A cytokine is a potent inflammatory cytokine that has been implicated in a growing list of autoimmune diseases, for example, multiple sclerosis, Crohn's disease, rheumatoid arthritis, psoriasis, systemic lupus erythematosus, and SS, as well as autoimmunity in animal models [3]. As the $\mathrm{T}_{\mathrm{H}} 17 / \mathrm{IL}-17 \mathrm{~A}$ system is considered to be an important factor in innate immunity that, in turn, regulates development of the adaptive immune response, it is not surprising that environmental microflora trigger IL-17A responses [34]. The consequence of $\mathrm{T}_{\mathrm{H}} 17 / \mathrm{IL}-17 \mathrm{~A}$ activation includes, in addition to the production the IL-17A family of cytokines, the production of IL-21, IL-22, chemokines (MIP-2, CXCL1, CXCL2, CXCL5), and matrix metalloproteases (MMP3 and MMP13) [16] all actively involved in tissue inflammation. Interaction of the IL-17A with its receptors evokes activation of IL-8, resulting in recruitment of neutrophils to the site of injury. However, the relationship between such early innate/inflammatory events mediated by the $\mathrm{T}_{\mathrm{H}} 17 / \mathrm{IL}-17 \mathrm{~A}$ system and the role $\mathrm{T}_{\mathrm{H}} 17$ cells play in subsequent autoimmunity remains unknown, especially in light of the multiple functions now associated with the $\mathrm{T}_{\mathrm{H}} 17$ cell populations. Thus, in the present study, we have attempted to elucidate the importance of the cytokine IL-17A per se in the development of SS and whether its function may be dependent on when it is expressed.

Results in which SS-non-susceptible C57BL/6J mice were cannulated with the Ad5-IL17A vector revealed that increased IL-17A expression could induce several pathological features of SS, irrespective of whether the mice (a) 7 weeks old mice cannulation

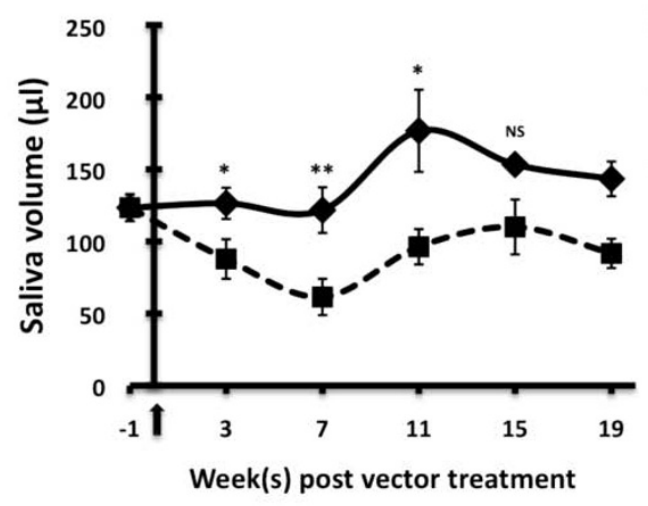

(b) 16 weeks old mice cannulation

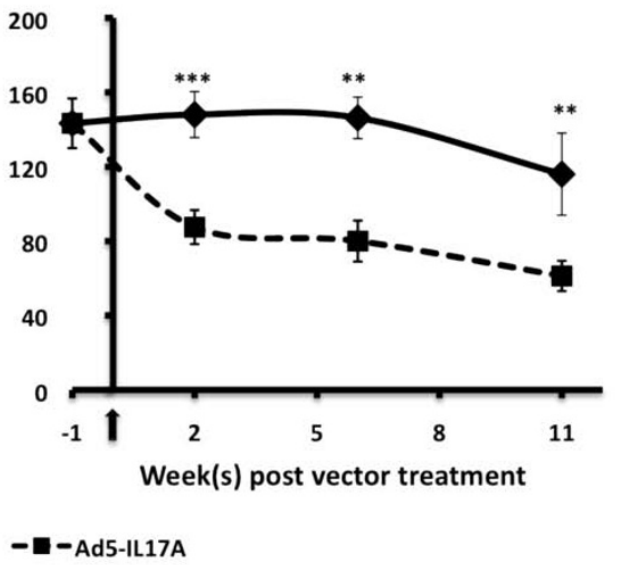

Figure 5 Stimulated saliva flow in treated C57BL/6J mice. One week prior to salivary gland cannulations with either Ad5-LacZ or Ad5-IL17A vector, stimulated saliva volumes were determined for individual mice within each of the four experimental groups: early treatment with Ad5LacZ $(n=10)$ or Ad5-IL17A $(n=11)$ at 7 wks of age (a) or late treatment with Ad5-LacZ $(n=10)$ or Ad5-IL17A ( $n=8)$ at 16 wks of age (b) Saliva was collected every three to five weeks post-treatment until the mice were euthanized. Statistical analysis was used to determine the significance between the Ad5-LacZ and Ad5-IL17A treated mice at each time point. (NS: not significant, $P={ }^{*}<0.05, P={ }^{* *}<0.01, P={ }^{* * *}$ 0.001). Arrows indicate the initial time point of vector cannulation. 
received the vector at 7 or 16 wks of age, two time points corresponding to innate and adaptive immune responses in SS-susceptible C57BL/6.NOD-Aec1Aec2 mice. This was noted by decreases in saliva production compared to control vector, elevated production of specific proinflammatory cytokines detected in sera, changes in the weak cytoplasmic/nuclear ANA patterns to nuclear specked staining on HEp2 cells and increased numbers of LF and IL17A positive cells present in the salivary glands at time of euthanasia. Interestingly, mice received Ad5IL17A at 7 wks of age showed a slight recovery of saliva secretion at 7 wks of treatment in contrast to mice received Ad5-IL17A at 16 wks of age. This observation might be supported by the differential immunological or biological response of mice at different ages and the effect of Ad5-IL17A exerted on the mice.

Previous studies have indicated that genes placed within Ad5 vectors are generally expressed transiently and locally restricted (that is, 7 to 14 days) [29]. The present study demonstrates that a rapid and significant increase in the levels of plasma IL-17A was affected at 12 days post-cannulation by the Ad5-IL17A transgene vector. Interestingly, this systemic increase in IL17 cytokine levels correlated with significant increases in splenic IL-17A secreting CD4+T cells that persisted at least 19 wks for mice treated at 7 wks of age and 11 wks for mice treated at 16 wks of age. These observations indicated that the Ad5 vector effect was longer than anticipated. Whether this effect might be due to an indirect secondary effect of the Ad5-IL17 vector is unknown. In addition, the systemic increase in IL17A production by local treatment of Ad5-IL17A presented in this study is consistent with previous studies by Bruce Baum's laboratory [35-38]. Adesanya et al. [39] has demonstrated that acinar cells can be punctured by retrograde salivary gland cannulation at a certain vector dosage. The injured acinar cells, which have compromised mucosal barrier integrity, allow for leakage of the vector systemically. Further studies by Kagami et al. [37] and He et al. [40] provided evidence that ductal cannulation of salivary glands can also have systemic effects due to the secretory nature of the salivary glands which are well endowed with protein synthesis organelles and secretory machinery.

Nevertheless, these observations are consistent with the concept that SS develops along specific biological processes in a sequential fashion and interference with this process alters development of disease [1-3]. Therefore, this study clearly indicates the pathogenic nature of IL-17A in inducing SS-like phenotypes when cannulated in the salivary glands.

Previous data have shown that lymphocytic infiltrates in the salivary glands secreting IL-17A and its related cytokines are more important in local glandular destruction. Staining salivary glands for IL-17A revealed that $\mathrm{C} 57 \mathrm{BL} / 6 \mathrm{~J}$ mice receiving Ad5-IL17A vector not only expressed significant levels of IL-17A, but that IL17A levels correlated with recruitment of inflammatory cells, specifically $\mathrm{B}$ and $\mathrm{T}$ cells, to the glands. This observation is important in light of the recent study suggesting IL-17A is a critical factor in the adaptive immune response by inducing the formation of germinal centers for the production of autoreactive antibodies [24]. Autoantibodies represent a major component in the onset of SS, thus the changes in the ANA profiles observed with sera of $\mathrm{C} 57 \mathrm{BL} / 6 \mathrm{~J}$ mice cannulated with the Ad5-IL17A vector indicate that IL-17A affects even the B cell compartment in SS-non-susceptible mice. The presence of LF and loss of saliva secretion raises an interesting question about the possible role of IL-17A in $B$ cell activation. As BAFF is capable of inducing $T_{H} 17$ cell differentiation in addition to regulating $B$ cell activation [41], the possible role of BAFF and IL17A in this phenomenon needs to be better defined in SS pathogenesis.

\section{Conclusions}

The capability of IL-17A to induce features of SS in SSnon-susceptible mice demonstrates the major role this cytokine plays in the development, and possible onset, of the autoimmune process. How this one cytokine affects the various features of autoimmunity, and at what level or time point, will require additional studies. More importantly, the study demonstrates that IL-17A might be a potential therapeutic target for SS.

\section{Abbreviations}

Ad5: adenovirus serotype 5; ANA: antinuclear antibodies; BAFF: B cell activating factor; CIA: collagen-induced arthritis; CXCL1: chemokine (C-X-C motif) ligand; EAE: experimental autoimmune encephalomyelitis; IFN- $\gamma$ : interferon-Y; IL: interleukin; LF: Iymphocytic focus; MIP-2: macrophage inflammatory protein-2; MMP: matrix metalloproteases; SS: Sjögren's syndrome.

\section{Acknowledgements}

The authors would like to thank Dr. Jay K. Kolls and Dr. Julie Bindas (Children's Hospital of Pittsburgh) for generously providing the Ad5-LacZ and Ad5-IL17A vectors and Dr. Phil Cohen for his critical reading of the manuscript and helpful suggestions. We greatly appreciate the assistance of Dr. Craig Meyers and Dr. Nicholas Muzyczka for the use of the microscope. Publication of this article was funded in part by the University of Florida Open-Access publishing Fund.

Funding: This work was supported by PHS grants K99DE018958 (CQN) from NIDCR, R21AI081952 (ABP) from NIAID and funds from the Sjögren's Syndrome Foundation and Center for Orphan Autoimmune Disorders. HY and JAC were supported by an NIH, NIDCR intramural research grant.

\section{Author details}

'Eli and Edythe L. Broad Institute, 7 Cambridge Center, Cambridge, MA 02142, USA. ${ }^{2}$ Department of Chemical Engineering, Massachusetts Institute of Technology, 77 Massachusetts Ave, E25-545, Cambridge MA 02139, USA ${ }^{3}$ Department of Oral Biology, University of Florida College of Dentistry, 1600 SW Archer Rd, Gainesville, FL 32610, USA. ${ }^{4}$ Center for Orphan Autoimmune Disorders, University of Florida College of Dentistry, 1600 SW Archer Rd, 
Gainesville, FL 32610, USA. ${ }^{5}$ National Institute of Dental and Craniofacial Research, NIH, 10 Center Drive MSC 1190, Bethesda, MD 20892, USA. ${ }^{6}$ Department of Pathology, Immunology \& Laboratory Medicine, University of Florida College of Medicine, 1600 SW Archer Rd, Gainesville, FL 32610, USA.

\section{Authors' contributions}

JAC produced and determined the titers of the Ad5-LacZ and Ad5-IL17A viral vectors. $\mathrm{HY}$ and $\mathrm{BL}$ performed retrograde ductal cannulations/ instillations of the vectors into the salivary glands. CQN designed the study, performed saliva flow, flow cytometry, histology and statistical analyses, and prepared the manuscript. WC carried out the ANA staining. ABP assisted in the manuscript preparation. All authors read and approved the final manuscript.

\section{Competing interests}

The authors declare that they have no competing interests.

Received: 20 September 2010 Revised: 30 November 2010 Accepted: 23 December 2010 Published: 23 December 2010

\section{References}

1. Nguyen CQ, Cha SR, Peck AB: Sjögren's syndrome (SjS)-like disease of mice: the importance of $B$ lymphocytes and autoantibodies. Frontiers in Bioscience 2007, 12:1767-1789.

2. Nguyen $\mathrm{CQ}$, Peck AB: Unraveling the pathophysiology of Sjogren syndrome-associated dry eye disease. Ocul Surf 2009, 7:11-27.

3. Lee BH, Tudares MA, Nguyen CQ: Sjogren's syndrome: an old tale with a new twist. Arch Immunol Ther Exp (Warsz) 2009, 57:57-66.

4. Brayer JB, Cha S, Nagashima H, Yasunari U, Lindberg A, Diggs S, Martinez J, Goa J, Humphreys-Beher MG, Peck AB: IL-4-dependent effector phase in autoimmune exocrinopathy as defined by the NOD.IL-4-gene knockout mouse model of Sjogren's syndrome. Scand J Immunol 2001, 54:133-140.

5. Cha S, Brayer J, Gao J, Brown V, Killedar S, Yasunari U, Peck AB: A dual role for interferon-gamma in the pathogenesis of Sjogren's syndrome-like autoimmune exocrinopathy in the nonobese diabetic mouse. Scand J Immunol 2004, 60:552-565.

6. Nguyen KH, Brayer J, Cha S, Diggs S, Yasunari U, Hilal G, Peck AB Humphreys-Beher MG: Evidence for antimuscarinic acetylcholine receptor antibody-mediated secretory dysfunction in nod mice. Arthritis Rheum 2000, 43:2297-2306.

7. Nguyen CQ, Gao JH, Kim H, Saban DR, Cornelius JG, Peck AB: IL-4-STAT6 signal transduction-dependent induction of the clinical phase of Sjogren's syndrome-like disease of the nonobese diabetic mouse. $J$ Immunol 2007, 179:382-390.

8. Nguyen CQ, Hu MH, Li Y, Stewart C, Peck AB: Salivary gland tissue expression of interleukin-23 and interleukin-17 in Sjogren's syndrome: Findings in humans and mice. Arthritis Rheum 2008, 58:734-743.

9. Sakai A, Sugawara Y, Kuroishi T, Sasano T, Sugawara S: Identification of IL18 and Th17 cells in salivary glands of patients with Sjogren's syndrome, and amplification of IL-17-mediated secretion of inflammatory cytokines from salivary gland cells by IL-18. I Immunol 2008, 181:2898-2906.

10. Harrington $L E$, Hatton RD, Mangan $P R$, Turner $H$, Murphy $T L$, Murphy KM, Weaver CT: Interleukin 17-producing CD4+ effector T cells develop via a lineage distinct from the Thelper type 1 and 2 lineages. Nat Immunol 2005, 6:1123-1132.

11. Park $H$, Li Z, Yang XO, Chang SH, Nurieva R, Wang YH, Wang Y, Hood L, Zhu Z, Tian Q, Dong C: A distinct lineage of CD4 T cells regulates tissue inflammation by producing interleukin 17. Nat Immunol 2005, 6:1133-1141.

12. Veldhoen M, Hocking RJ, Atkins CJ, Locksley RM, Stockinger B: TGFbeta in the context of an inflammatory cytokine milieu supports de novo differentiation of IL-17-producing T cells. Immunity 2006, 24:179-189.

13. Bettelli $E$, Carrier $Y$, Gao W, Korn T, Strom TB, Oukka M, Weiner HL, Kuchroo VK: Reciprocal developmental pathways for the generation of pathogenic effector TH17 and regulatory T cells. Nature 2006, 441:235-238

14. Mangan PR, Harrington LE, O'Quinn DB, Helms WS, Bullard DC, Elson CO, Hatton RD, Wahl SM, Schoeb TR, Weaver CT: Transforming growth factorbeta induces development of the $\mathrm{T}(\mathrm{H}) 17$ lineage. Nature 2006, 441:231-234
15. Ivanov II, McKenzie BS, Zhou L, Tadokoro CE, Lepelley A, Lafaille JJ, Cua DJ, Littman DR: The orphan nuclear receptor RORgammat directs the differentiation program of proinflammatory IL-17+ T helper cells. Cell 2006, 126:1121-1133.

16. Weaver $C T$, Hatton RD, Mangan PR, Harrington LE: IL-17 family cytokines and the expanding diversity of effector T cell lineages. Annu Rev Immunol 2007, 25:821-852

17. Kastelein RA, Hunter CA, Cua DJ: Discovery and biology of IL-23 and IL-27: related but functionally distinct regulators of inflammation. Annu Rev Immunol 2007, 25:221-242.

18. Zhou L, Lopes JE, Chong MM, Ivanov II, Min R, Victora GD, Shen Y, Du J, Rubtsov YP, Rudensky AY, Ziegler SF, Littman DR: TGF-beta-induced Foxp3 inhibits $\mathrm{T}(\mathrm{H}) 17$ cell differentiation by antagonizing RORgammat function. Nature 2008, 453:236-240.

19. Duerr RH, Taylor KD, Brant SR, Rioux JD, Silverberg MS, Daly MJ, Steinhart AH, Abraham C, Regueiro M, Griffiths A, Dassopoulos T, Bitton A, Yang H, Targan S, Datta LW, Kistner EO, Schumm LP, Lee AT, Gregersen PK, Barmada MM, Rotter Jl, Nicolae DL, Cho JH: A genome-wide association study identifies IL23R as an inflammatory bowel disease gene. Science 2006, 314:1461-1463

20. Hue S, Ahern P, Buonocore S, Kullberg MC, Cua DJ, McKenzie BS, Powrie F, Maloy KJ: Interleukin-23 drives innate and T cell-mediated intestinal inflammation. J Exp Med 2006, 203:2473-2483.

21. Cua DJ, Sherlock J, Chen Y, Murphy CA, Joyce B, Seymour B, Lucian L, To W, Kwan S, Churakova T, Zurawski S, Wiekowski M, Lira SA, Gorman D, Kastelein RA, Sedgwick JD: Interleukin-23 rather than interleukin-12 is the critical cytokine for autoimmune inflammation of the brain. Nature 2003, 421:744-748

22. Ye $P$, Rodriguez $F H$, Kanaly $S$, Stocking KL, Schurr J, Schwarzenberger $P$, Oliver P, Huang W, Zhang P, Zhang J, Shellito JE, Bagby GJ, Nelson S, Charrier K, Peschon JJ, Kolls JK: Requirement of interleukin 17 receptor signaling for lung CXC chemokine and granulocyte colony-stimulating factor expression, neutrophil recruitment, and host defense. J Exp Med 2001, 194:519-527.

23. Schwarzenberger P, La Russa V, Miller A, Ye P, Huang W, Zieske A, Nelson S, Bagby GJ, Stoltz D, Mynatt RL, Spriggs M, Kolls JK: IL-17 stimulates granulopoiesis in mice: use of an alternate, novel gene therapy-derived method for in vivo evaluation of cytokines. J Immunol 1998, 161:6383-6389.

24. Hsu HC, Yang P, Wang J, Wu Q, Myers R, Chen J, Yi J, Guentert T, Tousson A, Stanus AL, Le TV, Lorenz RG, Xu H, Kolls JK, Carter RH, Chaplin DD, Williams RW, Mountz JD: Interleukin 17-producing T helper cells and interleukin 17 orchestrate autoreactive germinal center development in autoimmune BXD2 mice. Nat Immunol 2008, 9:166-175.

25. Zheng C, Baum BJ: Evaluation of promoters for use in tissue-specific gene delivery. Methods Mol Biol 2008, 434:205-219.

26. Kok MR, Yamano S, Lodde BM, Wang J, Couwenhoven RI, Yakar S, Voutetakis A, Leroith D, Schmidt M, Afione S, Pillemer SR, Tsutsui MT, Tak PP, Chiorini JA, Baum BJ: Local adeno-associated virus-mediated interleukin 10 gene transfer has disease-modifying effects in a murine model of Sjogren's syndrome. Hum Gene Ther 2003, 14:1605-1618.

27. Kok MR, Voutetakis A, Yamano S, Wang J, Cotrim A, Katano H, Bossis I, Chiorini JA, Tran SD, Tak PP, Baum BJ: Immune responses following salivary gland administration of recombinant adeno-associated virus serotype 2 vectors. J Gene Med 2005, 7:432-441.

28. Lodde BM, Mineshiba F, Wang J, Cotrim AP, Afione S, Tak PP, Baum BJ: Effect of human vasoactive intestinal peptide gene transfer in a murine model of Sjogren's syndrome. Ann Rheum Dis 2006, 65:195-200.

29. Delporte C, Redman RS, Baum BJ: Relationship between the cellular distribution of the alpha(v)beta3/5 integrins and adenoviral infection in salivary glands. Lab Invest 1997, 77:167-173.

30. Cha S, Nagashima H, Brown VB, Peck AB, Humphreys-Beher MG: Two NOD Idd-associated intervals contribute synergistically to the development of autoimmune exocrinopathy (Sjogren's syndrome) on a healthy murine background. Arthritis Rheum 2002, 46:1390-1398.

31. Brayer J, Lowry J, Cha S, Robinson CP, Yamachika S, Peck AB, HumphreysBeher MG: Alleles from chromosomes 1 and 3 of NOD mice combine to influence Sjogren's syndrome-like autoimmune exocrinopathy. J Rheumatol 2000, 27:1896-1904.

32. Nguyen CQ, Sharma A, Lee BH, She JX, Mclndoe RA, Peck AB: Differential gene expression in the salivary gland during development and onset of 
xerostomia in Sjogren's syndrome-like disease of the C57BL/6.NODAec1Aec2 mouse. Arthritis Res Ther 2009, 11:R56.

33. Nguyen CQ, Sharma A, She JX, Mclndoe RA, Peck AB: Differential gene expressions in the lacrimal gland during development and onset of keratoconjunctivitis sicca in Sjogren's syndrome (SJS)-like disease of the C57BL/6.NOD-Aec1Aec2 mouse. Exp Eye Res 2009, 88:398-409.

34. Bettelli E, Korn T, Oukka M, Kuchroo VK: Induction and effector functions of $\mathrm{T}(\mathrm{H}) 17$ cells. Nature 2008, 453:1051-1057.

35. Zheng C, Voutetakis A, Kok MR, Goldsmith CM, Smith GB, Elmore $S$, Nyska A, Vallant M, Irwin RD, Baum BJ: Toxicity and biodistribution of a first-generation recombinant adenoviral vector, in the presence of hydroxychloroquine, following retroductal delivery to a single rat submandibular gland. Oral Dis 2006, 12:137-144.

36. O'Connell BC, Zheng C, Jacobson-Kram D, Baum BJ: Distribution and toxicity resulting from adenoviral vector administration to a single salivary gland in adult rats. J Oral Pathol Med 2003, 32:414-421.

37. Kagami H, O'Connell BC, Baum BJ: Evidence for the systemic delivery of a transgene product from salivary glands. Hum Gene Ther 1996, 7:2177-2184

38. Wang J, Voutetakis A, Mineshiba F, Illei GG, Dang H, Yeh CK, Baum BJ: Effect of serotype 5 adenoviral and serotype 2 adeno- associated viral vector-mediated gene transfer to salivary glands on the composition of saliva. Hum Gene Ther 2006, 17:455-463.

39. Adesanya MR, Redman RS, Baum BJ, O'Connell BC: Immediate inflammatory responses to adenovirus-mediated gene transfer in rat salivary glands. Hum Gene Ther 1996, 7:1085-1093.

40. He X, Goldsmith CM, Marmary Y, Wellner RB, Parlow AF, Nieman LK Baum BJ: Systemic action of human growth hormone following adenovirus-mediated gene transfer to rat submandibular glands. Gene Ther 1998, 5:537-541.

41. Doreau A, Belot A, Bastid J, Riche B, Trescol-Biemont MC, Ranchin B, Fabien N, Cochat P, Pouteil-Noble C, Trolliet P, Durieu I, Tebib J, Kassai B, Ansieau S, Puisieux A, Eliaou JF, Bonnefoy-Berard N: Interleukin 17 acts in synergy with $B$ cell-activating factor to influence $B$ cell biology and the pathophysiology of systemic lupus erythematosus. Nat Immunol 2009, 10:778-785.

doi:10.1186/ar3207

Cite this article as: Nguyen et al:: Pathogenic effect of interleukin-17A in induction of Sjögren's syndrome-like disease using adenovirusmediated gene transfer. Arthritis Research \& Therapy 2010 12:R220

\section{Submit your next manuscript to BioMed Central and take full advantage of:}

- Convenient online submission

- Thorough peer review

- No space constraints or color figure charges

- Immediate publication on acceptance

- Inclusion in PubMed, CAS, Scopus and Google Scholar

- Research which is freely available for redistribution

Submit your manuscript at www.biomedcentral.com/submit 